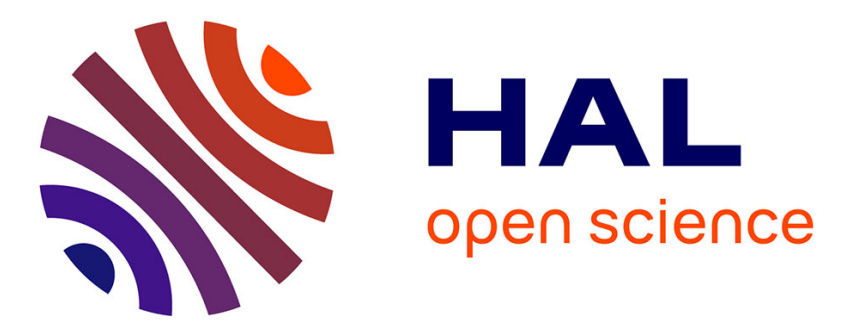

\title{
Instant controlled pressure drop extraction of lavandin essential oils: Fundamentals and experimental studies
}

Colette Besombes, Baya Berka-Zougali, Karim Allaf

\section{To cite this version:}

Colette Besombes, Baya Berka-Zougali, Karim Allaf. Instant controlled pressure drop extraction of lavandin essential oils: Fundamentals and experimental studies. Journal of Chromatography A, 2010, 1217 (44), pp.6807-6815. 10.1016/j.chroma.2010.08.050 . hal-02076638

\section{HAL Id: hal-02076638 \\ https: / hal-univ-rochelle.archives-ouvertes.fr/hal-02076638}

Submitted on 23 Apr 2019

HAL is a multi-disciplinary open access archive for the deposit and dissemination of scientific research documents, whether they are published or not. The documents may come from teaching and research institutions in France or abroad, or from public or private research centers.
L'archive ouverte pluridisciplinaire HAL, est destinée au dépôt et à la diffusion de documents scientifiques de niveau recherche, publiés ou non, émanant des établissements d'enseignement et de recherche français ou étrangers, des laboratoires publics ou privés. 


\title{
Instant controlled pressure drop extraction of lavandin essential oils: Fundamentals and experimental studies
}

\author{
Colette Besombes ${ }^{a}$, Baya Berka-Zougali ${ }^{a, b}$, Karim Allaf ${ }^{a, *}$ \\ a University of La Rochelle, Transfer Phenomena and Instantaneity in Agro-industry and Building - Pole Science and Technology, \\ Avenue Michel Crepeau, 17042 La Rochelle cedex 01, France \\ ${ }^{\mathrm{b}}$ University of Science and Technology Houari Boumediane USTHB, Laboratory of Analysis and Organic Functionality, \\ Scientific and Technological Research Center on Physico-Chemical Analysis (CRAPC), Bab Ezzouar, Algeria
}

\section{A R T I C L E I N F O}

\section{Article history:}

Received 7 June 2010

Received in revised form 17 August 2010

Accepted 20 August 2010

Available online 1 October 2010

\section{Keywords:}

Instant controlled pressure drop DIC

Essential oil

Hydrodistillation

Lavandin

Energy consumption

Modeling

\begin{abstract}
A B S T R A C T
Détente Instantanée contrôlée (DIC), French for Instant Controlled Pressure Drop, was performed on laboratory apparatus as well as on a pilot plant for proving its feasibility, and identifying the optimized processing conditions and recognizing the energy consumption and the quantity of water used for such an operation. GC-MS and SPME analysis of the extracts and residue material were carried out to assess the extracts and solid residues. The lavandin essential oils obtained by using the new DIC extraction process was studied, modeled and quantitatively and qualitatively compared to the conventional hydrodistillation method. The most important differences between the two essential oils were reflected in the yields, with 4.25 as against $2.3 \mathrm{~g} \mathrm{EO} / 100 \mathrm{~g}$ of raw matter, and in the extraction time, with $480 \mathrm{~s}$ as against some hours for respectively the DIC and the hydrodistillation operations. These differences have been previewed through the fundamental analysis. They can normally explain the great decreasing of energy consumption to be $662 \mathrm{kWh} / \mathrm{t}$ of raw material. The amount of water to be added was about $42 \mathrm{~kg}$ water/t of raw material.
\end{abstract}

(c) 2010 Elsevier B.V. All rights reserved.

\section{Introduction}

Lavandin Grosso, Lavandula intermedia var. Grosso, is a sterile clone issued from hybridization between Lavandula angustifolia Miller (formely L. officinalis ou L. vera) and Lavandula latifolia Vill (formely L. spica). This plant belongs to Lamiaceaes (or Labiatae) includes various varieties [1]. Several Lavandula species are essential oil plants [2]. Thus, Lavandula Grosso was selected because of its high essential oil yields as well as its very robust culture. However, the essential oil composition is somewhere different from that of Lavandula angustifolia mainly due to the presence of camphor. Moreover, this composition would present some changes through one or several factors possibly intervening synergistically such as genotype and agronomic factors ( $\mathrm{pH}$, fertilizer type, etc.), geographic origin, virus infection, etc. [3,4]. Composition and yields can vary depending on temperature and steam pressure of extraction process [5]. These essential oils can be used as fragrances for decorative cosmetic, fine perfume, shampoo, toilet soap and other toiletry applications as well as in non-cosmetic products such as household cleaners and detergents [2,6]. Its effects as insecticide or repulsive were studied without precisely iden-

\footnotetext{
* Corresponding author. Tel.: +33 546458766; fax: +33 546458616.

E-mail addresses: kallaf@univ-lr.fr, colette.besombes@univ-lr.fr (K. Allaf).
}

tifying the compounds responsible of such effects [7]. It presents anti-inflammatory, sedative and anti-bacterial attributes, closely linked to its major compounds as linalol and acetate of linalyl $[7,8]$. It would have a positive impact on homeostatic system. Ballabeni et al. [9] proved that lavender essential oils would have anti-platelet and antithrombotic activities.

Lavandin essential oils are usually extracted by steam distillation [1]. However, petroleum ether or hexane solvent extraction can be performed on lavandin inflorescences. The obtained product called as a concrete [7] would present numerous disadvantages $[10,11]$. Therefore, various other alternatives were tested. Thus Varona et al. [12], Reverchon et al. [13] and numerous other authors [14-18] used supercritical or subcritical fluid for extracting and fractioning essential oils. Microwave-assisted extraction was also largely used as new innovative techniques, such as SFME (Solvent Free Microwave Extraction) [19-21], VMHD (Vacuum Microwave HydroDistillation) [22,23], MASE (Microwave-Assisted Solvent Extraction) [24,25], MWHD (MicroWave HydroDistillation) [26,27], CAMD (Compressed Air Microwave Distillation) [28] and, finally, Microwave hydrodiffusion and gravity [29]. Flash-releasing is presented as brutal pressure variation [30,31]. In a synthetically work, Luque de Castro et al. [32] observed that at present no one of these techniques could perfectly answer all exigencies.

In the present work, we studied the new technology of instant controlled pressure drop DIC, as essential oil extraction process. 
DIC has been defined since 1988 and developed through various patents and several industrial realizations [33-37]. DIC technology has been used for the treatment of water-logged-archeological wood [38], post-harvesting and/or steaming of paddy rice [39], bacterial decontamination [36], swell-drying [40,41] and extraction by autovaporization of volatile molecules $[42,43]$.

\section{Fundamentals}

\subsection{Coupled heat and mass transfers in steam extraction}

Fundamental approach was carried out by Allaf et al. [44]. Aromatic plants were considered as porous material where coupled heat and mass transfer processes intervened. Flow heat can heat the product, but mainly assure a phase change (liquid-vapor) with a partial pressure strictly depending on the temperature. In the steam extraction, the external heat transfer from the saturated steam towards the external surface of the grain intervenes by convection and condensation. The mass transport (vapor of water and other volatile molecules) intervenes from the surface of grain within the surrounding environment to reach the condenser. The driving force, which is the gradient of essential oil partial pressure, can be intensified by increasing the difference of temperature between the exchange surface of the material and the condenser, and by setting them as close as possible one to each other.

In steam extraction, the exchange surface quickly raises the saturated steam temperature, and gradually spreads heat within the solid. The internal heat transfer is mainly processed by a similar conduction phenomenon. The porous structure, with a presence of air and water would allow vaporization/condensation phenomena to intervene inside of the holes within the product; the global phenomenon may be traduced by a conduction-type transfer where the gradient of temperature is conducted as a driving force with a higher value of effective conductivity. The main part of such heat flow is used to evaporate water and essential oils within the product holes.

The transfer of essential oils is assumed to be negligible under a liquid phase; the main mass transfer phenomenon is a diffusion of gas phase, which can be revealed by a Fick-type's law with the gradient of the partial pressure of each volatile compound as driving force. Whatever the type of the mass transfer within the plant as a porous material, it is assumed to be the limiting process because the effective mass diffusivity $D_{\text {eff }}$ is normally much lower than the heat diffusivity.

\subsection{Paradox of coupled heat and gas diffusion transfers}

The partial pressures of water and other volatile compounds inside the holes of the plant considered as porous material closely depend on the temperature through the thermodynamic liquid/gas equilibrium of the mixture of the volatile molecules.

The diffusion of any gas within a porous medium is controlled by the gradient of the concentration as driving force. Allaf et al. (submitted work) assumed in similar cases, the essential oil extraction necessarily implies an amount of heat capable to change the liquid into gas phase within the porous material. Allaf et al. [44] assumed the repartition of temperature was stationary during the major part of the operation because a main part of the heat would be only used for evaporating essential oils and water. As the external vapor (partial) pressure is saturated, one can postulate:

$-\lambda \vec{\nabla} \cdot \vec{\nabla} T+\varepsilon_{a b s} M_{e} L_{e} \frac{\partial}{\partial t}\left[\frac{p_{e}}{R T}\right]=0$

As the mass transfers of different compounds of essential oils would be governed by a similar Fick's law, the formulations of Allaf [45] were separately used. By neglecting the possible shrinkage

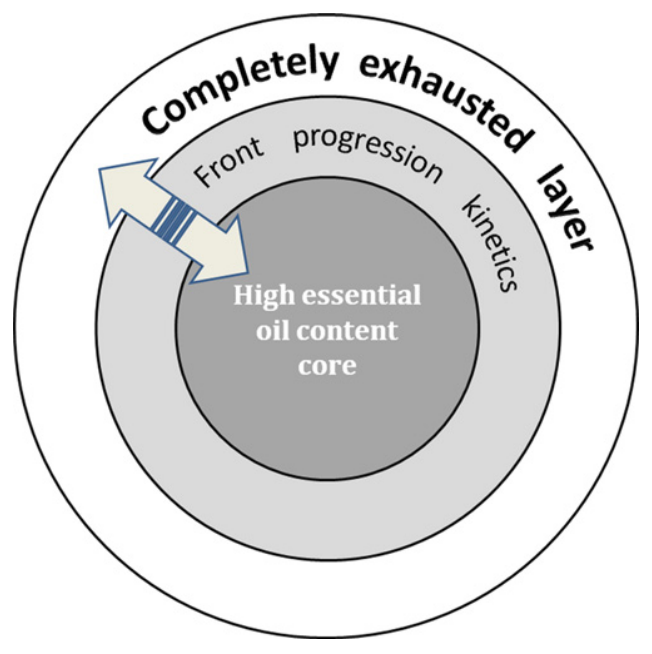

Fig. 1. The paradox motion of essential oil extraction implying "front progression" kinetics.

phenomena, one can assume:

$\left(\frac{p_{e}}{T}\right) \vec{V}_{e}=-D_{e f f e} \vec{\nabla}\left(\frac{p e}{T}\right)$

With one $r$ dimension, Eqs. (1) and (2) can be written respectively as:

$-\lambda \frac{\partial^{2} T}{\partial r^{2}}+\varepsilon_{a b s} M_{e} L_{e} \frac{\partial\left[p_{e} / R T\right]}{\partial t}=0$

$\left(\frac{p_{e}}{T}\right) V_{e}=-D_{e f f e}\left(\frac{\partial\left(p_{e} / T\right)}{\partial r}\right)$

On the other hand, as $\left(p_{e} / T\right)$ is as higher as the temperature is higher,

$\frac{\partial(p e / T)}{\partial T}>0$

the gradient of mass transfer is then directed from the surface to the sample core; the result is a paradox implying a motion completely opposite to that required for the sought operation of essential oil extraction. In the usual steam extraction of essential oils, the process is achieved by successive layers with "front progression" kinetics.

This may further explain that in the steam extraction, it is essential to reduce the granule size; a grinding pretreatment step is always required. However, it would be possible to remedy this situation and make a notable improvement in the kinetics by using microwave heating and/or moving volatile molecules with a mass transfer realized by the Total Pressure Gradient TPG process, using Darcy's law (see Fig. 1).

\subsection{Specificity of the DIC treatment}

In the DIC treatment conditions, Allaf et al. [44] assumed the total pressure of the mixture vapor and essential oils in the porous material intervening just after the pressure drops to be much higher than the external pressure. Therefore, whatever the structure of the porous plant, the mass transfer operation within this porous matrix has to be performed from the core towards the surrounding medium through the gradient of the total pressures. The Darcy-type law can traduce this transfer:

$\rho_{m} V_{m}=-\frac{K}{v_{m}} \frac{\partial p}{\partial r}$

By considering mass balance and continuity laws, and by integrating between the hole (whose radius $R_{0}$ ) and the external radius $R_{S}$ 
of the spherical shape, Allaf et al. (submitted work) calculated the part $m_{m}$ of essential oil and vapor mixture removed as:

$m_{m}=\frac{4}{3} \pi R_{o}^{3} \frac{\langle M\rangle}{R T}\left(p_{o}-p_{\text {ext }}\right)$

Usually, the time $t_{v}$ of the stage (f) just after pressure drops must generally be defined for allowing the vapor mixture to be transported towards the surrounding medium and then collected.

One can calculate the amount of heat needed for this autovaporization as:

$Q=m_{m} L_{m}=m_{p} c_{p p}\left(T_{i}-T_{f}\right)$

The DIC process seems to be relevant in terms of remedying the disadvantages of the paradoxical phenomenon and greatly intensifying the essential oil extraction. It uses the autovaporization instead of (or coupled to) the evaporation process, and the Total Pressure Gradient TPG instead of the normal diffusion phenomenon.

\section{Materials and methods}

The main part of the present investigation was to study the effects of the total heating time $(t)$ and the number of cycles $(C)$ as DIC operating parameters, regarding the total yields as the dependent variable. The principle objective was to identify separately the impacts of evaporation and autovaporization phenomena through a macro-scale modeling. Indeed, as the DIC implies a high temperature treatment (here up to $160^{\circ} \mathrm{C}$ ), the partial pressure of vapor, and then the evaporation must be much higher than that of classical steam extraction which is usually performed at $100^{\circ} \mathrm{C}$. Nevertheless, the fundamental study already had proved that the autovaporization strictly linked to the pressure drop would greatly intervene in the extraction of the essential oils by DIC.

An experimental design was built intervening total thermal treatment time $t$ and the number of cycles $C$ which is the number of pressure drops. The first operating parameter must be correlated to the evaporation process while the second one must reveal the effect of the autovaporization by itself. This investigation was achieved according to the protocol shown in Fig. 2.

Nevertheless, treatments by steam distillation were performed as references to compare the DIC extraction yields and kinetics. An adequate statistical treatment of the data issued from the experimental work carried out in the present article allowed us to study, analyze, optimize and model the DIC extraction of essential oils.

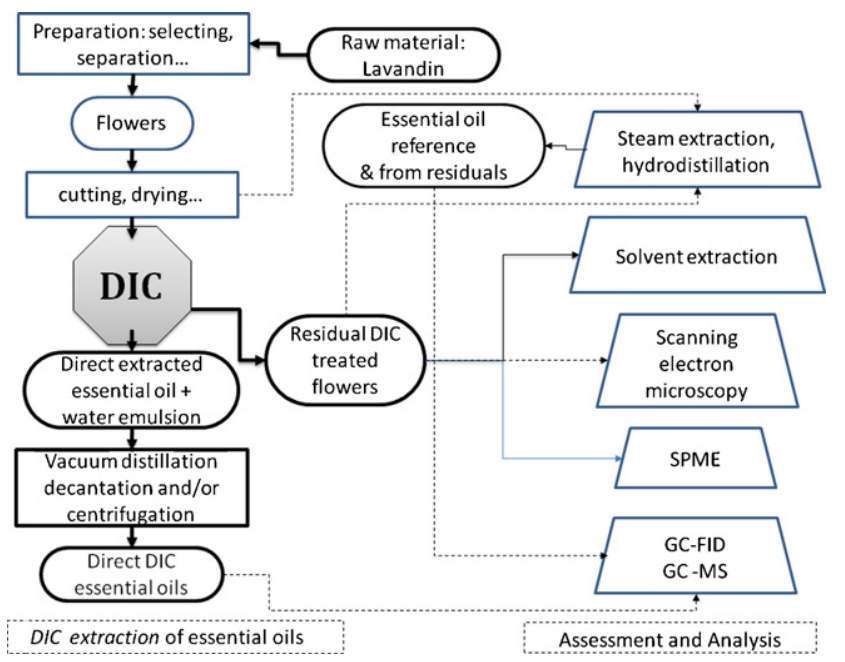

Fig. 2. Main stages of DIC - essential oil extraction.

\subsection{Raw material: the variety Grosso lavandin}

Lavender used in this study belonged to the variety Grosso lavandin; it was provided by the company Distillery Bleu Provence (Nyon, France). This raw material was harvested during summer, 2003, when weather was characterized by very high temperatures; its initial moisture content was $11 \mathrm{~g} \mathrm{H}_{2} \mathrm{O} / 100 \mathrm{~g}$ dry matter.

\subsection{Steam extraction}

The pilot plan steam extraction used in the present study was purchased from Pignat (Genas, France). Some modifications had allowed the equipment to be adequate for carrying out various treatments and quantifications of the amount of essential oil thus extracted. Raw material was placed on a tray positioned in the kettle above a quantity of boiling water and saturated steam such generated flowed within the raw material. The mixture of evaporated molecules was collected in a condenser. Some amount of hexane was added in order to capture, separate and quantify the extracted essential oil possibly present in the water. At the end of this separation process, condensed water reached the lower part of the extractor and the mixture of hexane/essential oils could be recuperated. After the hexane was removed, it was possible to estimate the essential oil yields.

\subsection{The instant controlled pressure drop (DIC) process}

In the present study, the raw lavandin was directly put in the DIC reactor processing vessel. Laboratory scale DIC reactor (Fig. 3) was defined and presented in various papers [46]. It is a 71 processing vessel with heating jacket, a $0.7 \mathrm{~m}^{3}$ vacuum tank with cooling water jacket, a water ring vacuum pump, and steam flow valves; a pneumatic valve assures an "instant" connection between the vacuum tank and the processing vessel; it can be opened in less than $0.1 \mathrm{~s}$. A pilot scale DIC reactor was also used; it is a 951 processing vessel and $5 \mathrm{~m}^{3}$ vacuum tank.

After placing the raw material in the treatment vessel and closing it, a first vacuum stage (about $5 \mathrm{kPa}$ ) was established in order to
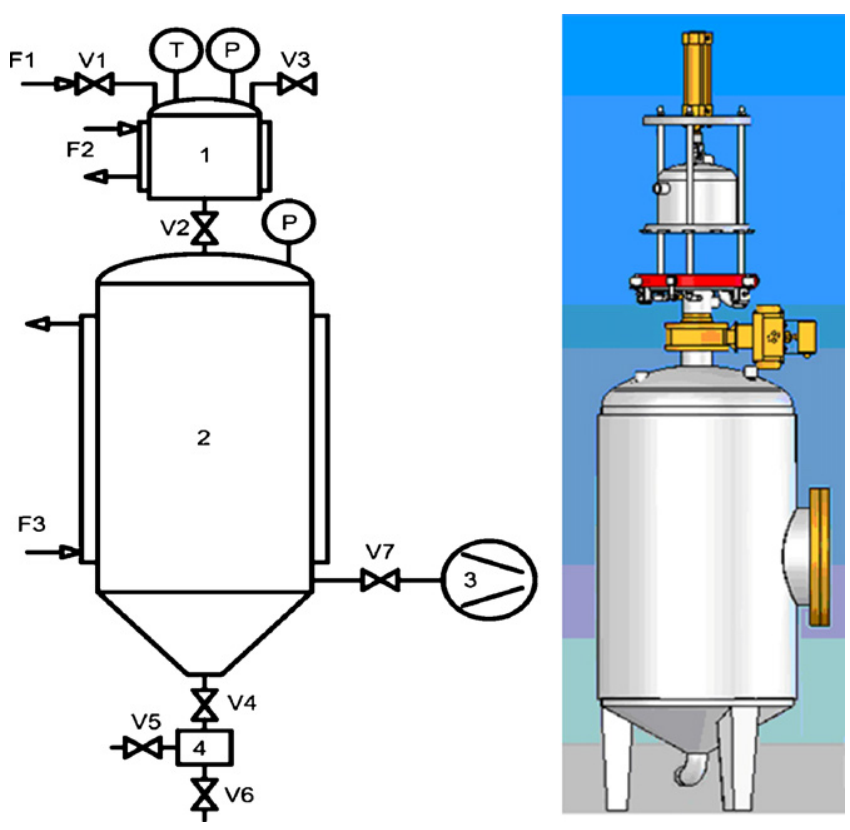

Fig. 3. Schematic diagram of the instant controlled pressure drop DIC apparatus: (1) autoclave with heating jacket; (V2) rapid valve; (2) vacuum tank with cooling water jacket; (3) vacuum pump; (4) extract container; F1 \& F2 steam flow; F3 cooling water flow. 


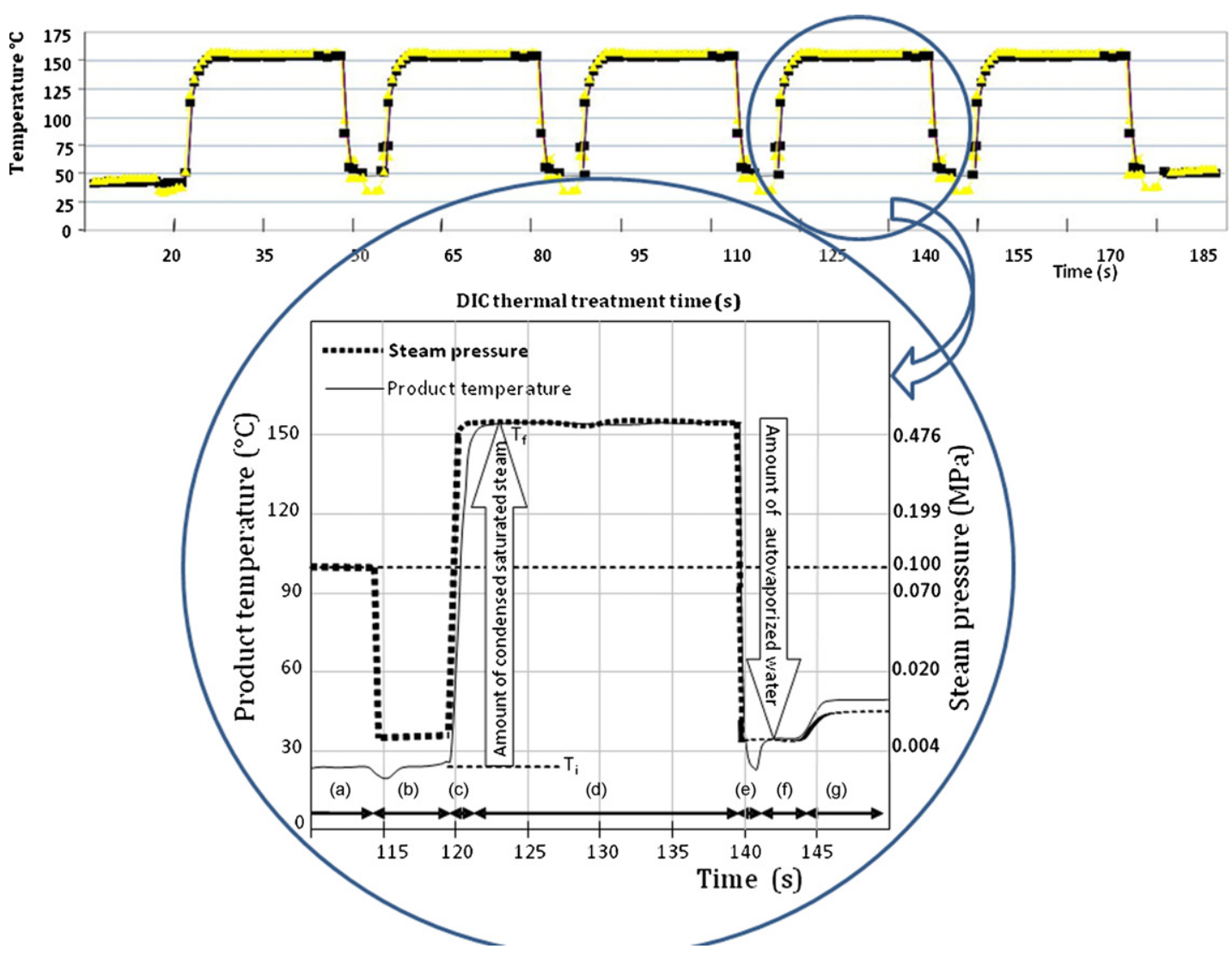

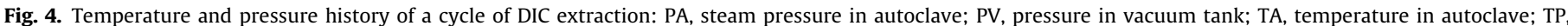

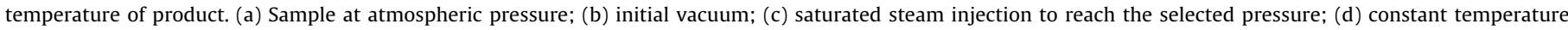

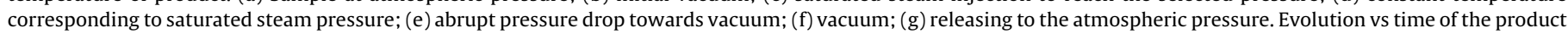
and vessel temperatures $\left( \pm 0.5^{\circ} \mathrm{C}\right)$ during a 1 cycle-DIC treatment.

remove the air presented in the vessel and, thus to assure close contact between the surface of the sample and the steam to be injected just after (Fig. 4 phase c). High pressure saturated steam used in our case was between 0.1 and $0.6 \mathrm{MPa}$ according to the experiment design, which allows the product temperature to be between 100 and $\left.160^{\circ} \mathrm{C}\right)$. This stage lasted 5-60 s and ended by an abrupt pressure drop towards vacuum $(5 \pm 0.2 \mathrm{kPa})$ by opening the pneumatic valve V2 (Fig. 3), which assured a decompression rate higher than $0.5 \mathrm{MPa} \mathrm{s}^{-1}$. In our case, several DIC-cycles were carried out and after finishing the treatment, sample is removed from the treatment vessel [46]. Fig. 4 gives the flow-sheet of this treatment. In our case, during the total thermal treatment time (phases $d$ of various cycles), a part of essential oils must evaporate; the instant pressure drops towards vacuum would normally simultaneously provoke an autovaporization of a part of water and volatile molecules (essential oils), a mechanical effect (expansion), and an instantaneous cooling of the product immediately stopping its thermal degradation.

The present study with lavandin started by some preliminary trials with various operating parameter levels (steam pressure, thermal treatment time and number of cycles).

In a second time, DIC extraction and classical steam distillation were studied in order to compare their own yields as well as the characteristics of final residual materials. DIC was achieved at constant saturated steam pressure of $0.6 \mathrm{MPa}$, with 2 cycles of 2 min of thermal treatment time for each, which was a total heating time of $4 \mathrm{~min}$.

In a third time, a specific experimental design [47] was adopted to identify and compare the effects of the total thermal treatment time and the number of cycles, chosen as operating parameters (or independent variables). It was to recognize the relative impacts of respectively evaporation and autovaporization phenomena. The extraction efficiency EE considered as the main response parameter (dependent variable) was calculated from GC-MS analysis by summing the areas, carried out on untreated lavandin (raw material) and residual solid after DIC treatments, as:

$\mathrm{EE}(\%)=\frac{\text { Essential oils in the raw material }- \text { Essential oils in DIC residual sample }}{\text { Essential oils in the raw material }}$

\subsection{Assessment protocol}

The measurement of water content by calibration with a drying oven at $105^{\circ} \mathrm{C}$ (model 800 , Memmert $\mathrm{GmbH}+\mathrm{Co} . \mathrm{KG}$, Schwabach, Germany) was carried out just before and just after DIC treatment.

The intrinsic $\rho_{\text {int }}$ (or skeletal or even true) density and the specific $\rho_{\text {spec }}$ (or apparent or solid) density of dried lavandin, both expressed in $\mathrm{kg} \mathrm{m}^{-3}$ were identified. The intrinsic density $\rho_{\text {int }}$ was measured using the Pycnometer method [48]. A pycnometer, model AccuPyc 1330, from Micromeritics (Verneuil en Halatte, France), with a cell of $3.5 \mathrm{~cm}^{3}$ was used after calibration at $20^{\circ} \mathrm{C}$, with a $2.425055 \mathrm{~cm}^{3}$ tungsten carbide sphere.

The specific density $\rho_{\text {spec }}$ was measured through the method defined by Louka et al. [49]. The specific density $\rho_{\text {spec }}$ was calculated according to the following equation:

$\rho_{\text {spec }}=\rho_{o}\left(\frac{m_{\text {prod }}}{m_{1}-m_{2}}\right)$ 
The absolute expansion ratio can be quantified by determining the ratio between the intrinsic and the specific densities.

$\varepsilon_{a b s}=\frac{\rho_{\text {int }}}{\rho_{\text {spec }}}$

The treatment texturing effect could be interpreted much better by using the relative expansion i.e. the ratio of the absolute expansions of the DIC treated residue and the raw material.

$\varepsilon_{\text {rel }}=\frac{\left(\varepsilon_{\text {abs }}\right)_{\mathrm{DIC}}}{\left(\varepsilon_{\text {abs }}\right)_{\mathrm{RM}}}=\frac{\left(\rho_{\text {int }} / \rho_{\text {spec }}\right)_{\mathrm{DIC}}}{\left(\rho_{\text {int }} / \rho_{\text {spec }}\right)_{\mathrm{RM}}}$

The analyses of absolute and relative expansion ratios were replicated according to the experimental design (between 3 and 5 times).

Micro-structural observations were made using an environmental type JEOL 5410LV FEI Quanta 200F, Philips (Croissy-sur-Seine, France) Scanning Electronic Microscope (SEM) at the Common Center of Analyses (CCA) of the University of La Rochelle. The samples were placed on a covered stud using carbon adhesive; the observations were developed in a partial vacuum (7 Pa) with an acceleration tension of $20 \mathrm{kV}$.

The initial untreated raw material samples, as well as various solid DIC treated samples were analyzed through a SPME system (model CombiPal, CTC Analytics AG, Zwingen, Switzerland) connected with a GC-MS system (GC model 3800 and MS model Saturn 2000, Cie Varian, Les Ulis, France).

In this study, a $50 \mu \mathrm{m} \times 30 \mu \mathrm{m}$ PDMS/DVB/CAR fiber was used. The fiber was conditioned prior to use according to supplier's prescriptions. Before sampling each fiber was reconditioned for $5 \mathrm{~min}$ in the GC injector port at $250^{\circ} \mathrm{C}$ to eliminate the possible remains on the coated fiber. The SPME parameters including the sample mass, the extraction temperature, the extraction time, and the desorption time were optimized. The final conditions were respectively: $0.1 \mathrm{~g}$, $70^{\circ} \mathrm{C}, 20 \mathrm{~min}$ et $10 \mathrm{~min}$.

During the extraction, an agitation was applied at $250 \mathrm{rpm}$, for $2 \mathrm{~s}$ and $4 \mathrm{~s}$ rest. The fixed quantity of sample was placed in a $10 \mathrm{ml}$ vial, which was tightly capped with a PTFE-face silicone septum (Supelco, Bellefonte, PA, USA) and placed into the sample tray of the CombiPaL (Varian, Les Ulis, France). Once the analysis was achieved, the fiber was automatically cleaned by heating according to supplier's instructions.

GC analysis conditions were optimized, with helium used as carrier gas, at a constant rate of $1 \mathrm{ml} / \mathrm{min}$. The column temperature was $60^{\circ} \mathrm{C}$ for $3 \mathrm{~min}$; it slowly increased $\left(2{ }^{\circ} \mathrm{C} / \mathrm{min}\right)$ up to $155^{\circ} \mathrm{C}$, and this end temperature was maintained for $3 \mathrm{~min}$. The detection, manifold, and transfer temperatures were 200,50 and $250{ }^{\circ} \mathrm{C}$ respectively.

\subsection{Statistical and experimental design protocol}

After having chosen the main operating parameters and explained their relevant variation range, through the preliminary tests and fundamental approach, special experimental studies were performed.

In order to achieve such relevant experimental studies, the RSM method with a five-level central composite rotatable experimental design method was adopted. In the present study, the saturated steam pressure used kept constant at $0.6 \pm 0.02 \mathrm{MPa}$ and the two
Table 1

Independent variables used in response surface methodology RSM at a fixed steam pressure value in the cases of dried Lavandin at $11 \mathrm{~g} \mathrm{H}_{2} \mathrm{O} / 100 \mathrm{~g}$ dry matter.

\begin{tabular}{|c|c|c|c|c|c|c|}
\hline & Coded level & $-\alpha$ & -1 & 0 & 1 & $+\alpha$ \\
\hline $\mathrm{X} 1=C$ & Number of cycles & 1 & 2 & 5 & 8 & 9 \\
\hline $\mathrm{X} 2=T$ & Treatment time (s) & 240 & 275 & 360 & 445 & 480 \\
\hline
\end{tabular}

$\alpha($ axial distance $)=\sqrt[4]{2^{N}}, N$ is the number of independent variables. In the present case: $N=2$ and $\alpha=1.4142$.

DIC operating parameters we studied were ranged as: (1) from $240 \pm 5$ to $480 \pm 5 \mathrm{~s}$ for the total thermal treatment time $t$, and (2) from 1 to 9 cycles for the number of cycles $C$ (Table 1 ). Moisture content just before DIC treatment was maintained constant $\left(11 \pm 0.3 \mathrm{~g} \mathrm{H}_{2} \mathrm{O} / 100 \mathrm{~g}\right.$ dry matter).

The trials were run at random to minimize the effects of unexpected variability of responses due to unrelated factors. DIC treatment experiments were then carried out using the operating conditions described in Table 2.

The statistical treatment of results was executed using the analysis design procedure of Statgraphics Plus software for Windows (1994, version 4.1, Levallois-Perret, France). Variance (ANOVA) was performed to determine significant differences between independent variables $(P \leq 0.05)$ and Pareto charts were introduced as well as general trends, response surface, empirical model coefficients, and $R^{2}$ were determined. The dependent variables had concerned process performances (in terms of efficiency) as well as the final extracted attributes: the response was expressed with a secondorder polynomial model of independent variables:

$Y=\beta_{o}+\sum_{i=1}^{n} \beta_{i} x_{i}+\sum_{i=1}^{n} \beta_{i i} x_{i}^{2}+\sum_{i=1}^{n} \beta_{i j} x_{i} x_{j}+\varepsilon$

where $Y$ was the response, $\beta_{0}, \beta_{i}, \beta_{i i}$ and $\beta_{i j}$ were the regression coefficients, $x_{i}$ were the independent variables, $\varepsilon$ was random error, $i$ and $j$ were the indices of the factors. Response surface methodology could be used to optimize the operating parameters by coupling various studied responses [47].

\section{Results and discussion}

\subsection{Comparative extraction yields of steam extraction and DIC}

Steam extraction was carried out with 21 of water in the kettle thus generating saturated steam and 11 in the extractor; an amount of $450 \mathrm{ml}$ hexane was used to effectively trap essential oils. A quantity of $24 \mathrm{~g}$ of lavandin was positioned on a tray in the kettle just above the water level. Once the first condensed drops reached the condenser, $2 \mathrm{~h}$ extraction time started. Distillation of hexane-essential oil mixture was achieved in order to completely remove hexane and the essential oils thus obtained had a yield of $2.3 \mathrm{gEO} / 100 \mathrm{~g}$ dry matter.

Operation of DIC extraction led to the condensation of a water-essential oil emulsion in the vacuum tank whose wall was cooled with a cold water flow within the double jacket. With the goal to quantify the yields, the emulsion was added to a similar amount of diethyl ether, which could trap the only essential oil molecules leading the water to be completely separated from the

Table 2

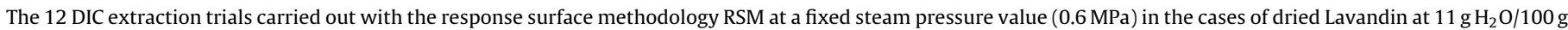
dry matter.

\begin{tabular}{|c|c|c|c|c|c|c|c|c|c|c|c|c|}
\hline & 1 & 2 & 3 & 4 & 5 & 6 & 7 & 8 & 9 & 10 & 11 & 12 \\
\hline Number of cycles & 5 & 2 & 1 & 5 & 2 & 8 & 9 & 8 & 5 & 5 & 5 & 5 \\
\hline Time of treatment (s) & 240 & 445 & 360 & 480 & 275 & 445 & 360 & 275 & 360 & 360 & 360 & 360 \\
\hline $\mathrm{EE}(\%)$ & 86.18 & 44.49 & -5.55 & 72.04 & -9.81 & 50.60 & 76.89 & 65.07 & 70.70 & 69.89 & 57.58 & 56.32 \\
\hline
\end{tabular}


emulsion. Then the diethyl ether was evaporated from its essential oil mixture; final extracted had a yield of $4.37 \mathrm{gEO} / 100 \mathrm{~g}$ dry matter.

These both values of steam distillation and DIC yields were sub-estimated, the first would be due to the condenser problems whereas the second would concern some amount of essential oils linked on the vacuum tank wall or within the vacuum pump (light compounds). However, these values were able to prove the ability of DIC to extract very quickly much higher yields of lavandin essential oils. In a shadow work, we proved that energy needed with DIC was much lower as well as the amount of water used.

\subsection{Microstructure of residual treated plant}

The SEM images of lavandin before and after DIC treatment revealed considerable structural differences. Before DIC treatment, plant had a compact and relatively homogeneous internal structure (Fig. 5). As expected, the DIC treatment radically changed the ultra-structure of lavandin, which had texture made up of cavities with different sizes, as shown in Fig. 6. These modifications were much lower than those obtained for swell-dried fruits and vegetables [50,51].

The different ultra-structures of lavandin, observed before and after DIC treatment, correlated with their specific densities. They would intervene much more in terms of technological behavior (higher ability of extraction and, possibly, higher availability of essential oil molecules).

Another specific situation of lavandin had concerned the tector hair in their alternation with the grandular trichomes (Fig. 5), which completely disappeared after DIC treatment (Fig. 6).

\subsection{Densities}

To compare the densities, lavandin samples were systematically dried till $4.5 \%$ for raw material and $3 \mathrm{gEO} / 100 \mathrm{~g}$ dry matter for DIC treated samples. Whatever the product types (raw material or DIC treated samples), the intrinsic density $\rho_{\text {int }}$ was constant at $1220 \pm 10 \mathrm{~kg} \mathrm{~m}^{-3}$. However, the specific density of raw material was $\rho_{\text {spec }}=381 \pm 6 \mathrm{~kg} \mathrm{~m}^{-3}$ and the DIC treated samples (at constant saturated steam pressure of $0.6 \mathrm{MPa}$, with 2 cycles of 2 min of thermal treatment time for each) had $\rho_{\text {spec }}=369 \pm 8 \mathrm{~kg} \mathrm{~m}^{-3}$, as shown in Table 3. DIC extraction implied a slight expansion effect with $107 \%$ as a relative expansion rate $\varepsilon_{\text {rel }}$. As the intrinsic density had the same value for both raw material and DIC treated samples, it could be established that $\varepsilon_{a b s}=\varepsilon_{\text {rel }}$ :

$\varepsilon_{\text {rel }}=\frac{\left(\rho_{\text {spec }}\right)_{\mathrm{RM}}}{\left(\rho_{\text {spec }}\right)_{\mathrm{DIC}}}=\frac{\left(\rho_{\mathrm{int}}\right)_{\mathrm{DIC}}}{\left(\rho_{\text {spec }}\right)_{\mathrm{DIC}}}=\varepsilon_{\text {abs }}$

\subsection{Relative impacts of evaporation and autovaporization}

Some works already had defined the DIC extraction of water (drying) or essential oil as autovaporization process [50,51]. No one had quantified the relative impacts of this phenomenon with the evaporation. However, DIC acted at high saturated steam pressure (between 0.2 and $0.6 \mathrm{MPa}$ ), which means at temperature higher than normal steam distillation, and although we did not obtain from bibliography thermodynamic data of lavandin essential oil compounds, it was obvious that, for any compounds, the higher the temperature, the higher the partially pressure. In this part of

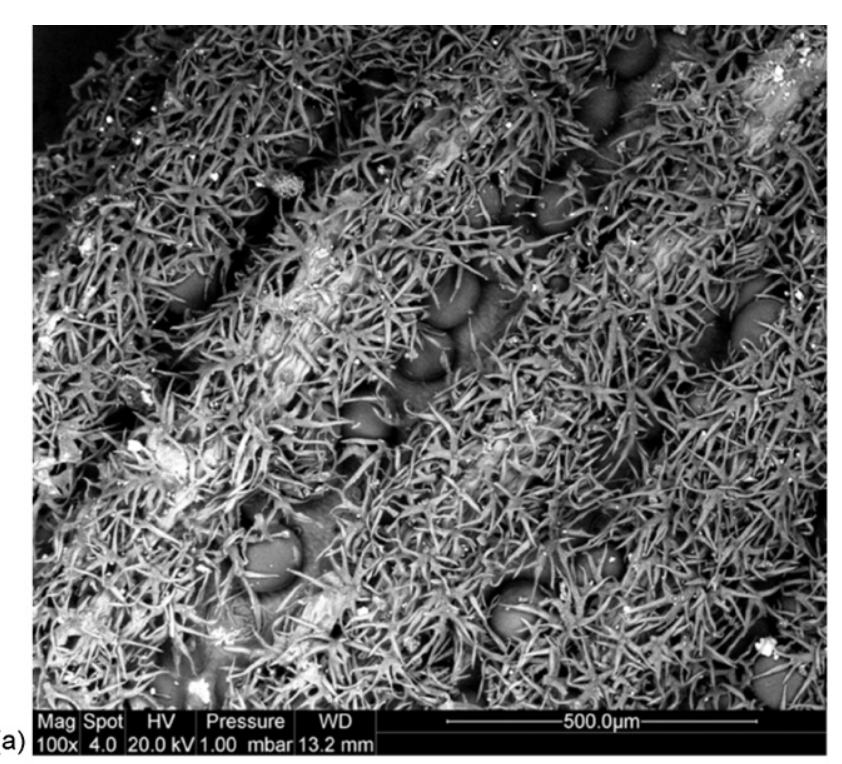

(a)

(b)

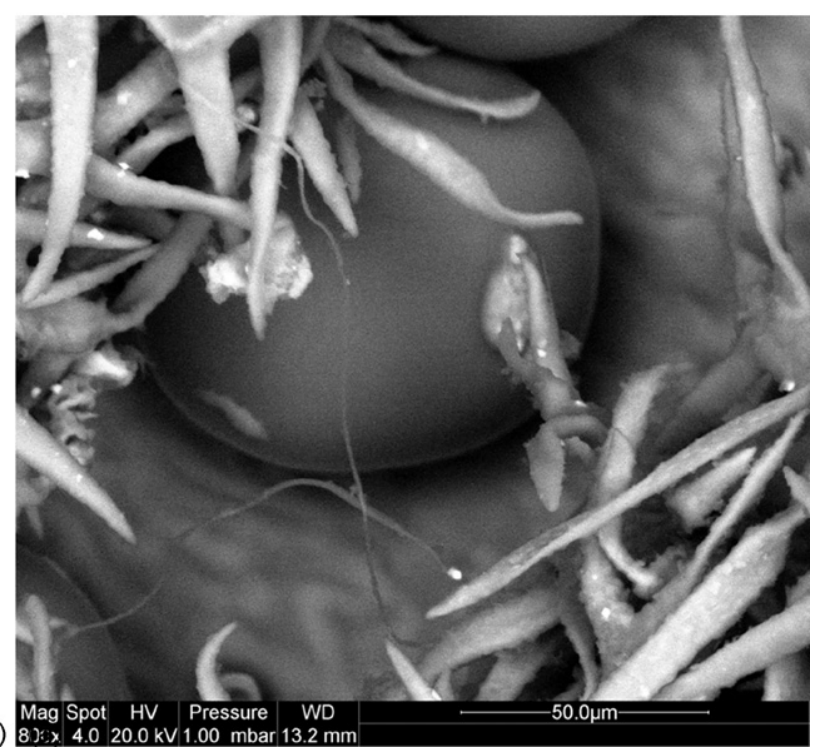

Fig. 5. Lavandin raw material, general view $(100 \times)$ and details $(800 \times)$.

our work, we aimed at comparing these two phenomena by using the experimental design of Table 2 [47] adopted with the total thermal treatment time and the number of cycles as the independent variables and the extraction efficiency EE as the response parameter (dependent variable). Pareto chart could be then introduced to provide facts needed for setting importance and priorities. It organized and displayed information to show the relative weight of various independent variables (here operative parameters) in terms of the dependent variable EE.

In the present case, effects of number of cycles $C$ and the total thermal treatment $t$ for EE are illustrated by the Standardized Pareto chart of Fig. 7. It can be inferred that the factor $C$ and $C^{2}$ (number of cycles), had a significant effect on the extraction process. Here also, it could be inferred that the number of cycles (revealing the pressure drop impact) was the only factor to have a profound effect

Table 3

Specific and intrinsic densities of Lavandin before and after DIC treatment at 0.6 MPa as steam pressure, 4 min as total thermal treatment time and 2 cycles.

\begin{tabular}{|c|c|c|c|}
\hline & Water content dry basis $W$ & Intrinsic density $\rho_{\text {int }}\left(\mathrm{kg} \mathrm{m}^{-3}\right)$ & Specific density $\rho_{\text {spec }}\left(\mathrm{kg} \mathrm{m}^{-3}\right)$ \\
\hline Raw material & $4.5 \mathrm{~g} \mathrm{H}_{2} \mathrm{O} / 100 \mathrm{~g}$ dry matter & $1230 \pm 16$ & $381 \pm 6$ \\
\hline DIC treated sample & $3 \mathrm{~g} \mathrm{H}_{2} \mathrm{O} / 100 \mathrm{~g}$ dry matter & $1210 \pm 6$ & $369 \pm 8$ \\
\hline
\end{tabular}




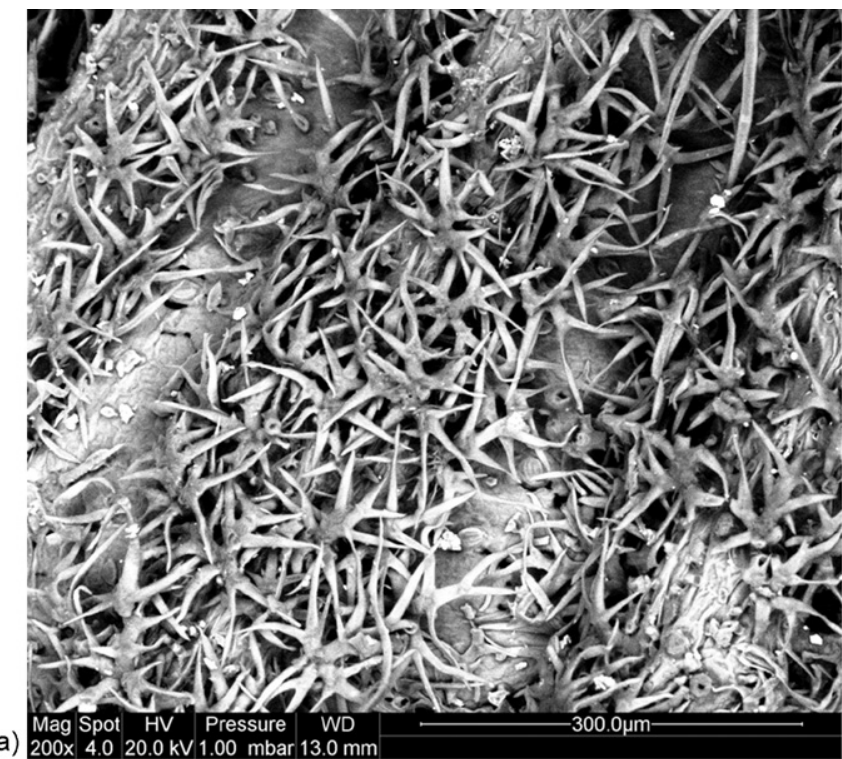

(a)

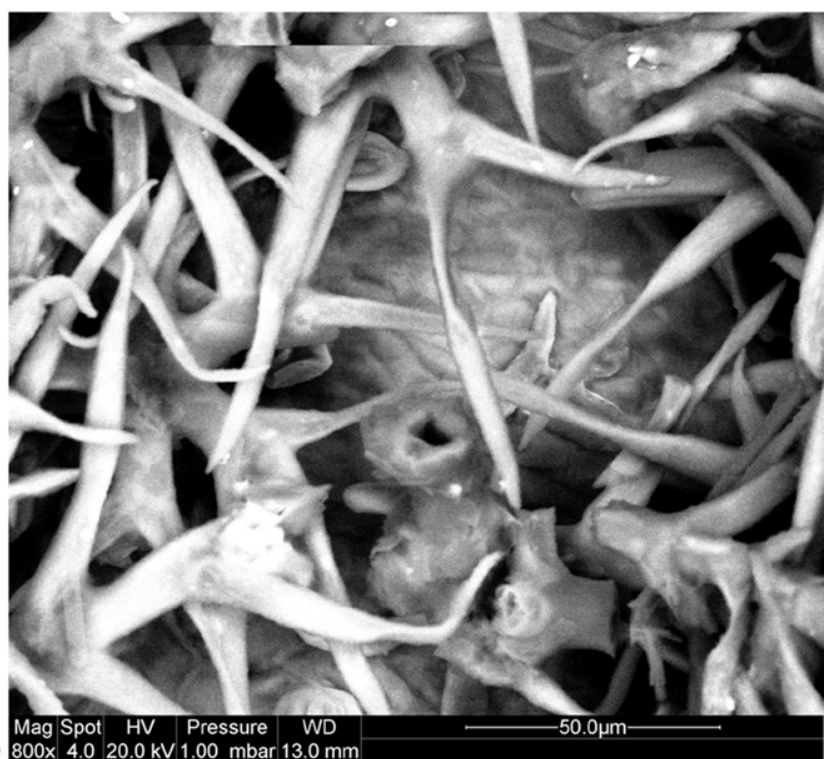

Fig. 6. Lavandin DIC treated samples, general view $(100 \times)$ and details $(800 \times)$.

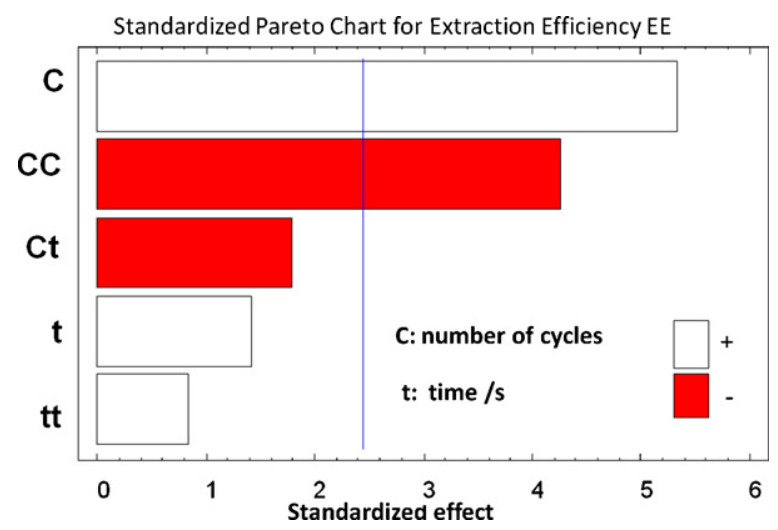

Fig. 7. Standardized Pareto chart.

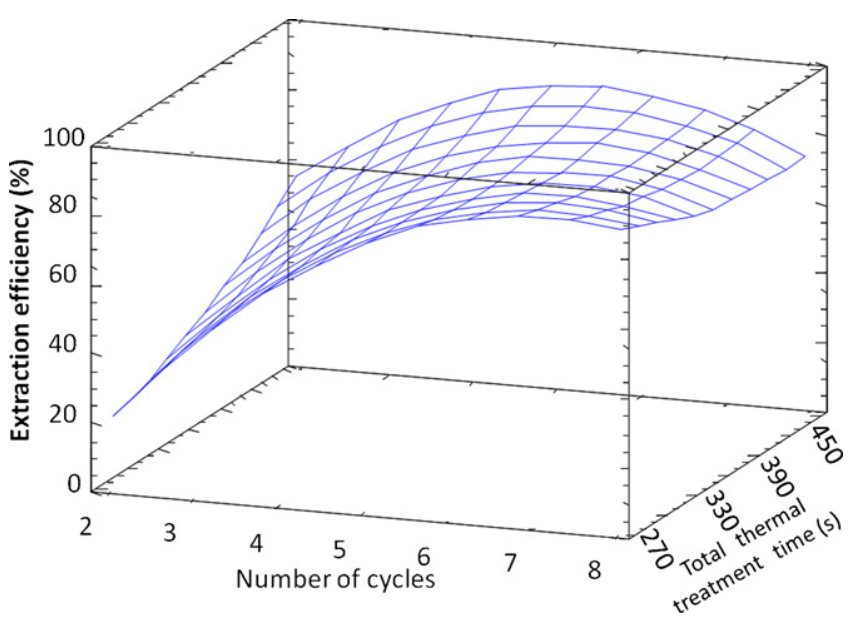

Fig. 8. The response surfaces to represent the total effect of operative parameters.

on the global essential oil extraction. Although the number of cycles $C$ appeared to be the main operative parameter, we note that longer $t$ can reduce the impact of $C$.

The response surfaces allowed us to represent the total effect of operative parameters. RSM optimization was used to show the impact of the operative factors in terms of extraction efficiency EE (Fig. 8). Thus, it was possible to identify the highest and the quickest DIC extraction process through the operation efficiency. Here, it was clear that the number of cycles (revealing the impact of the pressure drops) was the only factor to have a profound effect.

The mathematical relationship obtained with the statistical package Statgraphics was a polynomial equation representing the quantitative effect of process variables and their interactions on the measured response EE. The values of the coefficients of $C$ and $t$ were

Table 4

Sheet of flow and energy consumption of DIC treatment (with 0.6 MPa as steam pressure, 6 cycles for 4 min as total thermal treatment time) used at industrial scale for extracting essential oils from lavandin.

\begin{tabular}{|c|c|}
\hline Mass of raw material RM & $30 \mathrm{~kg}$ \\
\hline Volume of the processing vessel & $0.095 \mathrm{~m}^{3}$ \\
\hline Apparent density of RM & $381 \mathrm{~kg} \mathrm{~m}^{-3}$ \\
\hline Volume ratio in processing vessel & $84 \%$ \\
\hline Volume of processed material & $0.080 \mathrm{~m}^{3}$ \\
\hline Intrinsic (true) density of RM & $1220 \mathrm{~kg} \mathrm{~m}^{-3}$ \\
\hline Volume of steam in the processing vessel & $0.070 \mathrm{~m}^{3}$ \\
\hline Latent heat of water vaporization & $2450 \mathrm{~kJ} \mathrm{~kg}^{-1}$ \\
\hline Treatment temperature & $432 \mathrm{~K}$ \\
\hline Saturated steam pressure & $0.6 \mathrm{MPa}$ \\
\hline Mass of steam in the processing vessel & $0,21 \mathrm{~kg}$ \\
\hline Specific heat of Raw Material & $1.5 \mathrm{~kJ} \mathrm{~kg}^{-1} \mathrm{~K}^{-1}$ \\
\hline Heat of steam used for heating the product & $7262 \mathrm{~kJ}$ \\
\hline Heat of steam used per cycle & $516 \mathrm{~kJ}$ \\
\hline Total heat per cycle & $7778 \mathrm{~kJ}$ \\
\hline Number of cycles & 6 \\
\hline Total heat for the DIC extraction & $13 \mathrm{kWh}$ \\
\hline Total heat for the DIC extraction per $\mathrm{kg}$ of RM & $0.43 \mathrm{kWh} / \mathrm{kg} \mathrm{RM}$ \\
\hline Heat yield & $66 \%$ \\
\hline Heat needed/t & $646 \mathrm{kWh} / \mathrm{t} \mathrm{RM}$ \\
\hline Water needed per tonne RM & $42 \mathrm{~kg}$ \\
\hline Rate of used water & $66 \%$ \\
\hline Water used per tonne & $63 \mathrm{~kg}$ water/t RM \\
\hline $\begin{array}{l}\text { Electricity power (vacuum pump and } \\
\text { compressor) }\end{array}$ & $7.5 \mathrm{~kW}$ \\
\hline Extraction time & $240 s$ \\
\hline Hourly treatment capacity & $456 \mathrm{~kg} / \mathrm{h}$ \\
\hline $\begin{array}{l}\text { Total energy consumption per tonne of raw } \\
\text { material }\end{array}$ & $662 \mathrm{kWh} / \mathrm{t} \mathrm{RM}$ \\
\hline Essential oil yields & $4.4 \mathrm{~g} \mathrm{EO} / 100 \mathrm{~g}$ dry matter \\
\hline Hourly essential oil capacity & $20 \mathrm{~kg} \mathrm{EO} / \mathrm{h}$ \\
\hline $\begin{array}{l}\text { Total energy consumption/kg of lavandin } \\
\text { essential oils }\end{array}$ & $15 \mathrm{kWh} / \mathrm{kg}$ EO \\
\hline
\end{tabular}


related to the effect of these variables on the response EE. A positive value represented an effect that favors the operation, while a negative value indicated an antagonistic effect. This mathematical relationship is listed below:

$$
\begin{aligned}
\mathrm{EE}= & -119.005+56.9438 C+0.0615197 t-2.37428 C^{2} \\
& -0.067103 C t+0.000431365 t^{2}
\end{aligned}
$$

with $R^{2}=85.29 \%$.

The optimized operative conditions with the goal to maximize the extraction efficiency EE was calculated as an optimum value of $96.22 \%$, for $240 \mathrm{~s}$ as a total thermal treatment time $t$, and 6.4 as a theoretical value of the number of cycles $C$.

These $t$ and $C$ optimized values were substituted and used in experimental trials carried out at $0.6 \mathrm{MPa}$ as saturated steam pressure $P$, total thermal treatment time $t=240 \mathrm{~s}$, and $C=6$ cycles, which means $40 \mathrm{~s}$ of thermal treatment time for each cycle. The predicted value and the observed values were found to be in good agreement. In a shadow work (Table 4), we could calculate the energy consumption to be $0.110 \mathrm{kWh} / \mathrm{kg}$ and per cycle; it was to say a total of $662 \mathrm{kWh} / \mathrm{t}$ of raw material. The used water was about $42 \mathrm{~kg}$ water $/ \mathrm{t}$ of raw material.

\section{Conclusion}

The present research work confirmed the high relevance of DIC treatment as extraction process. At both fundamental and experimental points of view, this study allowed the DIC extraction process to be defined as a mainly autovaporization phenomenon; the contribution of evaporation to the extraction of essential oils was established to be very weak even negligible in the usual DIC processes.

In the case of lavandin Grosso, the DIC was defined and optimized as a quick and effective process of essential oil extraction. Compared with steam distillation, it was to note the lower energy consumption and water consumption (662 kWh and $42 \mathrm{~kg}$ water/t of raw material), with yields twice higher (4.37 as against $2.3 \mathrm{~g} \mathrm{EO} / 100 \mathrm{~g}$ dry matter). This would be correlated to an expansion effects which was noted through SEM analysis as well as density measurements.

Finally, it was not possible to collect thermodynamic data from bibliography concerning various compounds intervening in lavandin essential oils. In next works, it would be important to observe more precisely and separately the behavior of the main extracted molecules regarding the DIC operative conditions; various behaviors would then allow us to define a double fractioning through DIC extraction: during the autovaporization as well as by condensation.

\section{Nomenclature}

$C_{p p}$

$D_{\text {effe }}$

$K \quad$ permeability of the essential

$L_{e} \quad$ latent heat of vaporization of essential oils $\left(\mathrm{J} \mathrm{kg}^{-1}\right)$

$L_{m} \quad$ mean of the specific latent heat of vaporization of the mixture of essential oils and water $\left(\mathrm{J} \mathrm{kg}^{-1}\right)$

$\langle M\rangle \quad$ mean molar mass of the vapor and essential oil mixture

$m_{1} \quad$ mass of a volume $V$ of the cracking powder $(\mathrm{kg})$

$m_{2}$ a complementary mass of the powder $(\mathrm{kg})$, poured on the product to reach the same volume $V$

$M_{e} \quad$ molar mass of the essential oils $\left(\mathrm{kg} \mathrm{mol}^{-1}\right)$ $m_{m} \quad$ mass of the vapor mixture of the essential oils and water during a DIC cycle $(\mathrm{kg})$

$m_{p} \quad$ mass of the product $(\mathrm{kg})$,

$m_{\text {prod }} \quad$ mass of the dried lavandin $(\mathrm{kg})$

$p \quad$ total pressure, which is $p_{\text {globule }}$ the pressure of vapor mixture of water and essential oils in the "core of the solid" varying from $P_{o}$ at $t=$ zero towards $P_{\text {ext }}$, at $t \rightarrow \infty(\mathrm{Pa})$

$p_{e} \quad$ partial pressure of the essential oils in the material (Pa)

$R \quad$ ideal gas constant $\left(\mathrm{J} \mathrm{mol}^{-1} \mathrm{~K}^{-1}\right)$

$R_{O} \quad$ hole radius in the porous solid ( $\mathrm{m}$ )

$R_{S} \quad$ external radius of porous solid (m)

$T \quad$ temperature $(\mathrm{K})$

$t$ time (s)

$T_{f} \quad$ final temperature of the product $\left({ }^{\circ} \mathrm{C}\right)$

$T_{i} \quad$ initial temperature of the product $\left({ }^{\circ} \mathrm{C}\right)$

$\vec{V}_{e} \quad$ absolute velocity of essential oils within the porous solid $\left(\mathrm{ms} \mathrm{s}^{-1}\right)$

$\vec{V}_{m} \quad$ absolute velocity of the vapor mixture of essential oils and water within the porous solid $\left(\mathrm{m} \mathrm{s}^{-1}\right)$

$\varepsilon_{a b s} \quad$ absolute expansion rate (\%)

$\varepsilon_{\text {rel }} \quad$ relative expansion rate (\%)

$\lambda$ global conductivity of the porous wet material $\left(\mathrm{J} \mathrm{m}^{-1} \mathrm{~K}^{-1}\right)$

$v_{m} \quad$ kinematic viscosity of the mixture of essential oils and water vapor $\left(\mathrm{m}^{2} \mathrm{~s}^{-1}\right)$

$\rho_{m} \quad$ apparent density of the vapor mixture of essential oils and water $\left(\mathrm{kg} \mathrm{m}^{-3}\right)$

$\rho_{0} \quad$ density of the cracking powder $\left(\mathrm{kg} \mathrm{m}^{-3}\right)$

$\rho_{\text {int }} \quad$ intrinsic (or true) density of dried lavandin $\left(\mathrm{kg} \mathrm{m}^{-3}\right)$

$\rho_{\text {spec }} \quad$ specific (or apparent) density of dried lavandin $\left(\mathrm{kg} \mathrm{m}^{-3}\right)$

\section{References}

[1] F. Ségur, Etude du polymorphisme d'une population de lavande (Lavandula angustifolia Mill.); détermination de critères précoces de sélection. Thèse de doctorat, Université de Nantes (1990) 1990NANT10VS.

[2] M. Lis-Balchin, Lavender: The Genus Lavandula Med Aromatic Plants-Ind Profiles, vol. 29, 2002, p. 251, ISBN: 415284864.

[3] R. Bruni, M. Grazia Bellardi, G. Parrella, A. Bianchi, Physiol. Mol. Plant Pathol. 68 (2006) 189.

[4] N.S. Sangwan, A.H.A. Farooqi, F. Shabih, R.S. Sangwan, Plant Growth Regul. 34 (2001) 3.

[5] http://www.nda.agric.za/docs/EssOils_Lavender.pdf (2009).

[6] C.S. Letizia, J. Cocchiara, J. Lalko, A.M. Api, Food Chem. Toxicol. 41 (2003) 965.

[7] S. Cosimi, E. Rossi, P.L. Cioni, A. Canale, J. Stored Prod. Res. 45 (2009) 125.

[8] J.V. Larrondo, M. Agut, M.A. Calvo-Torras, Microbios 82 (1995) 171.

[9] V. Ballabeni, M. Tognolini, M. Chiavarini, M. Impicciatore, R. Bruni, A. Bianchi, E. Barocelli, Phytomedicine 11 (2004) 596.

[10] J. Crouzet, Arômes alimentaires, Techniques de l'ingénieur (2004) F 4100.

[11] M.M. Jimenez-Carmona, J.L. Uberab, M.D. Luque de Castro, J. Chromatogr. A 855 (1999) 625.

[12] S. Varona, A. Martin, M.J. Cocero, T. Gamsea, J. Supercrit. Fluids 45 (2008) 181.

[13] E. Reverchon, G. Della Porta, F. Senatore, J. Agric. Food Chem. 43 (1995) 1654.

[14] M. Perrut, Extraction par fluides supercritiques, Techniques de l'ingénieur J2770 (2003).

[15] V. Fernandez-Pérez, M.D. Luque de Castro, J. Chromatogr. A 902 (2000) 357.

[16] P.R. Venskutonis, Proceedings of the 38th International Symposium on Essential Oils, Graz, Autriche, 2007, p. 51.

[17] G. Wenqiang, L. Shufen, Y. Ruixiang, T. Shaokun, Q. Can, Food Chem. 101 (2007) 1558.

[18] S.M. Pourmortazavi, S.S. Hajimirsadeghi, J. Chromatogr. A 1163 (2007) 2.

[19] J.Y. Anizon, B. Lemaire, M. Surbled, Extraction assistée par micro-ondes, Techniques de l'ingénieur F3060 (2003).

[20] F. Chemat, M.E. Lucchesi, J. Smadja, Solvent free microwave extraction of volatile natural substances, US Pat. 0,187,340 A1, 2004.

[21] M.A. Ferhat, B.Y. Meklati, F. Chemat, Proceedings of the 38th International Symposium on Essential Oils, Graz, Autriche, 2007, p. 44.

[22] P. Mengal, B. Mompon, Method and plant for solvent-free microwave extraction of natural products, EP Pat. 698,076 B1, 1996.

[23] P. Mengal, D. Behn, M. Bellido Gil, B. Mompon, Parfums, cosmétiques, arômes 114 (1993) 66.

[24] K. Ganzler, A. Salgo, K. Valko, J. Chromatogr. 371 (1987) 299.

[25] J.R.J. Paré, Microwave extraction of volatile oils, US Pat. 5,338,557, 1994.

[26] E.E. Stashenko, B.E. Jaramillo, J.R. Martinez, J. Chromatogr. A 1025 (2004) 105

[27] E.E. Stashenko, B.E. Jaramillo, J.R. Martinez, J. Chromatogr. A 1025 (2004) 93.

[28] A.A. Craveiro, F.J.A. Matos, J.W. Alencar, M.M. Plumel, Flavour Fragance J. 4 (1989) 43. 
[29] M. Abert Viana, X. Fernandez, F. Visinonic, F. Chemat, J. Chromatogr. A 1190 (2008) 14.

[30] http://technofruits2001.cirad.fr/fr/brat.htm (juin 2005).

[31] http://www.inra.fr/layout/set/print/presse/enrichir_le_vin_en_aromes_et_ pigments_la _flash_detente.html (septembre 2006).

[32] M.D. Luque de Castro, M.M. Jiménez-Carmona, V. Fernandez-Pérez, Trends Anal. Chem. 18 (1999) 708.

[33] K. Allaf, N. Louka, J.M. Bouvier, F. Parent, M. Forget, Procédé de traitement de produits biologiques et installation pour la mise en œuvre d'un tel procédé, Brevet français issu de la demande n ${ }^{\circ}$ FR 93/09728 du 6 Août 1993 - délivré le 13/10/95 et publié sous le n ${ }^{\circ}$ F2708419 en date du 10/02/95.

[34] K. Allaf, F. Cioffi, S. Rezzoug, M.P. Contento, N. Louka, E. Sanya, Procédé de traitement en vue de sécher, conserver, préserver, restaurer ou consolider le bois naturel, détérioré ou gorgé d'eau, et installation pour la mise en œuvre d'un tel procédé, Brevet français issu de la demande FR n 97/14513 en date du 19/11/97.

[35] K. Allaf, N. Louka, Z. Maache-Rezzoug, S.-A. Rezzoug, E. Debs-Louka, A. Habba, G. Abraham, Procédé de traitement thermique, thermo-mécanique, hydro-thermique et hydro-thermo-mécanique de produits divers solides ou pulvérulents, pâteux, liquides ou mélange de liquides, applications de ce procédé et installation pour la mise en œuvre de ce procédé. Brevet français issu de la demande $\mathrm{N}^{\circ}$ FR 98/11106 du 04/09/98 sous priorité de la demande française $\mathrm{N}^{\circ}$ 98/02032 du 19/02/98 publiée le 20 Août 1999 sous le n`2 774911.

[36] K. Allaf, E. Debs-Louka, N. Louka, G. Abraham, Procédé de réduction ou d'élimination d'organismes, de microorganismes, de pasteurisation et de stérilisation des produits solides en morceaux ou pulvérulents et installation pour la mise en œuvre d'un tel procédé. Demande de Brevet français № 98/02032 du $19 / 02 / 98$.

[37] K. Allaf, E. Debs-Louka, N. Louka, N. Cochet, G. Abraham, Procédé de réduction ou d'élimination d'organismes ou micro-organismes, de pasteurisation et/ou de stérilisation et installation pour la mise en œuvre d'un tel procédé, Demand of French Patent n 94/14832; 09/12/1994.

[38] E.A. Sanya, S.A. Rezzoug, K. Allaf, Sci. Technol. Cultural Heritage 14 (2005) 37.
[39] C. Duong Thai, Etude de l'application du procédé hydro-thermique dans le traitement de différents types de riz: procédé d'étuvage et micro-expansion par détente instantanée contrôlée et impact sur les propriétés fonctionnelles, Thèse de doctorat, Université de La Rochelle, 2003.

[40] N. Louka, K. Allaf, J. Food Sci. 67 (2002) 3033.

[41] M. Al Haddad, S. Mounir, V. Sobolik, K. Allaf, Int. J. Food Eng. 4 (2008), art 9.

[42] O. Bekhai, K. Allaf, DIC: a new method of extraction of essential oils. Rapport interne DTAI, Département Génie Chimique, UTC, Compiègne, p. 5/10, 4 mai 1994.

[43] C. Besombes, N. Albitar, K. Allaf, O. Barkat, Proceedings of the 38th International Symposium on Essential Oils, Graz, Autriche, 2007, p. 47.

[44] K. Allaf, C. Besombes, M. Kristiawan, V. Sobolik, Extraction mechanisms of essential oils; in essential oils: green extraction and applications, Arvinder Singh Bhalla (JEOBP) 3/14/2 Prem Nagar, Dehra Dun, 248004 India, 2009.

[45] K. Allaf, Transfer Phenomena and Industrial Applications, Teaching book published by the Lebanese University, Faculty of Science, 1982.

[46] M. Kristiawan, V. Sobolik, K. Allaf, J. Chromatogr. A 1192 (2008) 306

[47] D. Benoist, Y. Tourbier, S. Germain-Tourbier, Plan D’Expériences: Construction et Analyse, Lavoisier Tec \& Doc, London, 1994, p. 208.

[48] R.L. Lynch, J. Thomas, Pycnometer, as United States Patent 4,095,473 (Application Number: 05/797648, Publication Date: 06/20/1978, Filing Date: 05/16/1977).

[49] N. Louka, Maîtrise de la qualité des produits agro-alimentaires séchés; modification texturale et réduction du coût énergétique par Détente Instantanée Contrôlée " DIC " vers le vide, Conception et réalisation d'un nouveau procédé industriel, Thèse de doctorat, 1996.

[50] S. Mounir, K. Allaf, Proceedings of the European Drying Conference AFSIA 2005, 13-14 May, Paris, France, 2005.

[51] S. Mounir, M. Alrifai, P. Le Yondre, K. Allaf, Proceedings of the COSM'ING 2007 4th International Symposium 27-29 juin, Saint-Malo, France, Ed. LAVOISIER, 2007. 